\title{
Simultaneous and successive contrast with delay of reward*
}

\author{
N. J. MACKINTOSH $\dagger$ and JANET LORD \\ Dalhousie University, Halifax, Nova Scotia, Cariada
}

\begin{abstract}
In Experiment 1. rats showed no evidence of a successive negative contrast effect (NCE) when shifted from immediate reward to a 15 -sec delay of reward. Experiment II provided a direct comparison of NCE in both successive and simultaneous paradigms. As in Experiment I, there was no evidence of a successive NCE, but a reliable simultaneous NCE was observed. These results add support for the view that simultaneous and successive NCEs are not due to a single, common process.
\end{abstract}

Spence (1956, pp. 155-163) and Harker (1956) reported that rats, trained to perform an instrumental response for an immediate reward, showed at most only a gradual decline in performance when shifted to a condition in which the reward was delayed by 5 or $10 \mathrm{sec}$. They found no evidence of the type of negative contrast effect commonly observed when rats are shifted from a large to a small reward (Crespi, 1942). More recently, Shanab and McCuiston (1970) found some slight evidence of negative contrast when rats were shifted from immediate to a 15 -sec delay of reward, and McHose and Tauber (1972) found a substantial effect when rats were shifted from a $10-\mathrm{sec}$ to a $30-\mathrm{sec}$ delay; Shanab (1971), however, found no significant contrast effect following a shift from immediate reward to a 30 -sec delay of reward.

The results of these studies of successive contrast appear to differ from those obtained by Beery (1968) and Chechile and Fowler (1973), studying delay of reward in a simultaneous contrast paradigm. In studies of successive contrast, experimental Ss are exposed to one condition of reinforcement and then shifted to another; in studies of simultaneous contrast, experimental Ss are concurrently exposed to different conditions of reinforcement signaled by different stimuli. In each case, the performance of experimental Ss is compared with that of a control group exposed to only a single condition of reinforcement. In their studies of simultaneous contrast, Beery and Chechile and Fowler observed a significant negative contrast effect (NCE): Ss simultaneously exposed to immediate and either a 10-sec or a 9-sec delay of reward ran more slowly to the delayed reward than did a control group exposed only to the delayed reward.

Simultaneous and successive NCEs have often been attributed to the same process: both Amsel (1967) and Black (1968), for example, have argued that they are a consequence of frustration or inhibition generated by the receipt of a reward less favorable than that which was expected. It is a matter of some consequence,

\footnotetext{
*This research was supported by Grant APA 259 from the National Research Council of Canada.

+ Requests for reprints should be sent to N. J. Mackintosh, who in now at the Laboratory of Experimental Psychology, University of Sussex. Brighton. BN1 9QY, England.
}

therefore, to know whether similar operations (e.g., an increase in delay of reward) produce similar results in both experimental situations. The results of the above studies suggest that they may not, but a conclusion based on a comparison between different experiments is obviously open to question. One purpose of the present experiments, therefore, was to provide an explicit comparison of the effects of delay of reward in successive and simultaneous paradigms.

Experiment I was a straightforward study of successive contrast. A control group of rats was trained to run an alley for a $15-\mathrm{sec}$ delay of reward, while an experimental group was initially trained with immediate reward and then shifted to the 15 -sec delay. When this procedure failed to produce any NCE, Experiment II employed a slightly different design for the study of successive contrast, which brought the procedure closer to that employed in simultaneous paradigms. Experiment II then provided a direct comparison of the two paradigms.

\section{EXPERIMENT I}

\section{Method}

The Ss were 20 male hooded COBS rats obtained from Charles River Labs, St. Constant, Quebec. They weighed between 250 and $300 \mathrm{~g}$ upon arrival in the laboratory, and were maintained at $80 \%$ of their ad lib weights by controlled feeding after each day's trials. The apparatus consisted of a pair of black and white runways, each $0.93 \mathrm{~m}$ long, $0.11 \mathrm{~m}$ wide, and $0.22 \mathrm{~m}$ deep (inside measurements), covered with hinged Plexiglas lids. The last $0.28 \mathrm{~m}$ of each runway was separated from the remainder of the alley by sliding guillotine doors, and served as the goalbox. At the far end of each goalbox was a container with a tightly fitting aluminum lid, which could be slid sideways by $\mathrm{E}$ to provide access to food. A single gray startbox $(0.22 \mathrm{~m}$ long $)$ could be placed in front of either the black or the white runway, and was separated from them by an opaque gray guillotine door. A microswitch on the startbox door and a photocell $0.22 \mathrm{~m}$ inside the goalboxes controlled a clock which recorded running times to the nearest $0.10 \mathrm{sec}$.

The Ss were assigned randomly to groups and given 2 days of pretraining. On the first day, they explored the runway for $10 \mathrm{~min}$; on the second day, they were placed in the goalbox five times and fed. On these and all subsequent trials, reward consisted of two 190-mg Noyes pellets. Training began after the second day of pretraining; on the first 2 days, $S$ s received 5 trials a day; thereafter, 10 training trials were given each day. A trial was started by placing $S$ in the startbox, waiting for 3 sec. and 


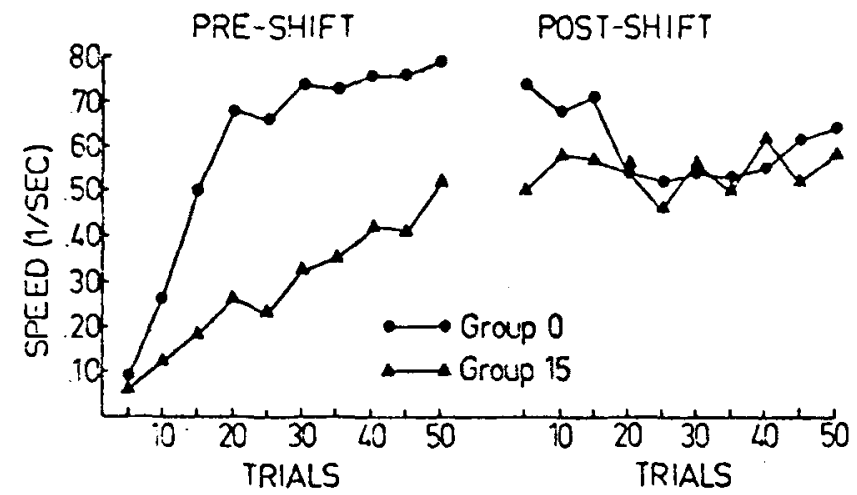

Fig. 1. Experiment I: Mean running speeds during preshift and postshift.

opening the startbox door. As soon as S entered the goalbox, the guillotine door was closed behind it. All trials were rewarded, but the lid to the food compartment was shut at the start of the trial. On immediately rewarded trials, the lid was opened as soon as $\mathrm{S}$ broke the photobeam; on delayed trials, the lid was opened after a 15-sec delay. The intertrial interval was 3-5 $\mathrm{min}$.

Group $O$ received 50 trials with immediate reward, followed by 50 trials with a $15-\mathrm{sec}$ delay of reward. Group 15 received 100 trials with the 15-sec delay of reward. Half of each group were run in the black runway, and half in the white runway.

\section{Results}

Running times were converted to reciprocals, and averaged over 5-trial blocks. The resulting speed scores for the two main groups are shown in Fig. 1. During the 50 preshift trials, Group $\mathrm{O}$ ran substantially faster than Group 15. An analysis of variance performed on these scores revealed significant effects of delay $[F(1,16)=$ $42.98, \mathrm{p}<.001]$ and of trial blocks $[\mathrm{F}(9,144)=81.61$, $p<.001]$, as well as a significant interaction between the two $[F(9,144)=11.00, p<.001]$.

Following the increase in delay of reward for Group O, their speed of running fell within 20 trials to about the same level as that of Group 15, but inspection of Fig. 1 reveals no evidence of any NCE. Statistical analysis revealed that there was a just-significant interaction between groups and trials $[F(9,144)=1.97$, $p<.05]$, but an analysis performed over Trials 21.50 of the postshift period revealed no significant effects.

\section{EXPERIMENT II}

Experiment I employed relatively standard procedures for studying successive contrast. These differ in a number of respects from the procedures typically used in studies of simultaneous contrast. In order to provide a more analytic comparison of the two paradigms, Experiment II employed somewhat unusual procedures for both conditions.

The two groups used to study successive contrast received 50 preshift trials in the black alley with either immediate or delayed reward, followed by 50 postshift trials with delayed reward in the white alley. The two groups used to study simultaneous contrast also received
50 preshift trials in the black alley, with either immediate or delayed reward: during their 50 postshift trials, both groups were run alternately in the black and in the white alley, with the experimental group continuing to receive immediate reward in the black alley interspersed with delayed reward in the white alley, and the control group receiving delayed reward in both alleys. Thus, the only difference between the present successive and simultaneous designs was that during postshift trials, the simultaneous groups continued to receive trials in the black alley interspersed with trials in the white alley, while the successive groups were run only in the white alley.

\section{Method}

The Ss were 40 rats from the same stock as those used in Experiment I, and the apparatus was the same. With only a few exceptions, the procedures were the same as in Experiment $I$. Pretraining involved a 5-min preexposure to both alleys and five rewarded placements in each goalbox. Preshift training was exactly the same as in Experiment I, with groups receiving either immediate or 15-sec delay of reward in the black alley. Postshift training for the two successive groups was the same as in Experiment I, except that all trials were in the white alley. The two simultaneous groups also received 10 postshift trials per day for 5 days, with 5 trials each day to the black alley and 5 to the white alley (the sequence determined by Gellermann orders). Both simultaneous groups received 15-sec delay of reward in the white alley, while Group $\mathrm{O}$ continued to receive immediate reward in the black alley, and Group 15 continued to receive $15-\mathrm{sec}$ delay of reward in the black alley. The experiment was run in two replications, with half the Ss from each of the four groups in each replication.

\section{Results}

Running times were converted to reciprocals and averaged over five-trial blocks. The resulting speed scores are shown for the two successive groups in Fig. 2, and for the two simultaneous groups in Fig. 3. During preshift training, the groups receiving immediate reward ran faster than those receiving delayed reward. An analysis of variance performed on the preshift scores of all four groups revealed a significant effect of delay $[\mathrm{F}(1,36)=35.25, \mathrm{p}<.001]$ and of trial blocks

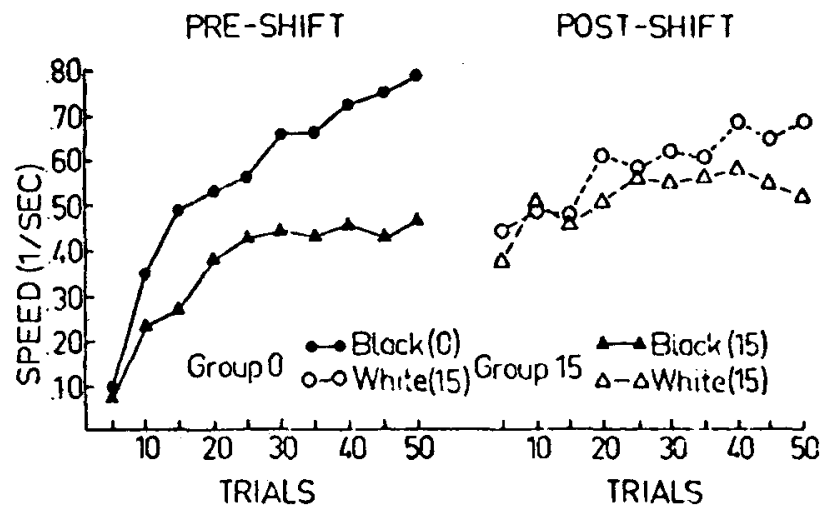

Fig. 2. Experiment II: Mean running speeds for successive groups during preshift and postshift. 
$[\mathrm{F}(9,324)=121.84, \mathrm{p}<.001]$, as well as a significant interaction $[F(9,324)=6.64, p<.001]$. There was no difference between the two simultaneous and the two successive groups, who were, of course, treated similarly during preshift trials $(F<1)$.

The shift from the black to the white alley produced some disruption of performance in both successive groups, especially for Group $\mathrm{O}$, which experienced an increase in delay of reward at the same time. Except over Trials 5-10, however, Group O continued to run somewhat faster than Group 15, and there was, therefore, no evidence of any NCE. An analysis of postshift scores revealed a significant effect of trial blocks $[\mathrm{F}(9,162)=9.20, \mathrm{p}<.001]$, but no significant difference between the two groups $[F(1,18)=1.48$, $\mathrm{p}>.05$ ] and no significant interaction between groups and trials $[F(9,162)=1.22, p>.05]$. Performance over Trials 1-10 was examined more closely for evidence of a transient NCE. On 6 of these 10 trials, Group O ran faster than Group 15, and on no trial was the difference between the two groups, as evaluated by a t test, significant at the .05 level.

The postshift data for the two simultaneous groups, shown in Fig. 3, suggest that here a NCE did occur: the critical comparison is between the performance of the two groups in the white alley, in which both groups received a $15 \cdot \mathrm{sec}$ delay of reward. It can be seen from Fig. 3 that Group O ran more slowly than Group 15 over the entire postshift phase. An analysis of variance performed on these postshift scores revealed a significant interaction between groups and stimuli $[F(1,18)=$ $58.57, \mathrm{p}<.001]$, while subsidiary analyses revealed not only that Group $\mathrm{O}$ ran more rapidly in the black alley than Group $15[\mathrm{~F}(1,18)=9.14, \mathrm{p}<.01]$, but that they also ran more slowly in the white alley $[F(1,18)=4.56$, $\mathrm{p}<.05$ ]

\section{DISCUSSION}

The results of Experiment I confirmed that a moderate increase in delay of reward may not produce a successive NCE in rats. Experiment II provided a direct comparison between simultaneous and successive contrast designs, and confirmed that a simultaneous NCE may occur under conditions insufficient to produce a successive NCE. Neither of these findings, of course, excludes the possibility that a more substantial increase in delay of reward would produce a successive NCE.

The discrepancy between simultaneous and successive paradigms, observed here for delay of reward, has in fact been noted in at least two other situations. Flaherty, Riley, and Spear (1973), for example, obtained very similar results in a study in which rats were exposed to shifts in the concentration of sucrose used as reinforcement. A simultaneous design produced a significant NCE, while a successive design produced none. Similarly, Gonzalez and Powers (1972) found that goldfish exposed to different magnitudes of reward in a

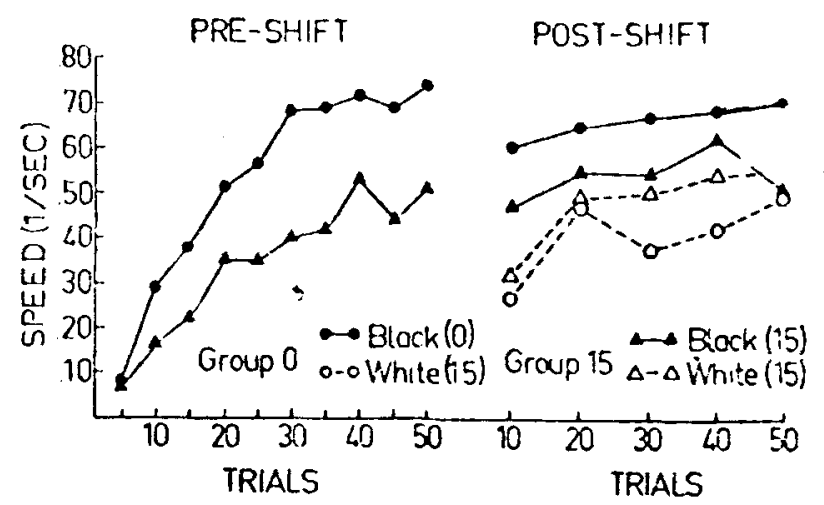

Fig. 3. Experiment II: Mean running speeds for simultaneous groups during preshift and postshift.

simultaneous design showed a significant NCE, while several analogous studies have failed to find evidence of NCEs in successive designs with fish (e.g., Lowes \& Bitterman, 1967; Gonzalez, Potts, Pitcoff, \& Bitterman, 1972; Raymond, Aderman, \& Wolach, 1972; Mackintosh, 1971).

In the present study, the only difference between simultaneous and successive designs was that the simultaneous design ensured that experimental Ss (Group 0 ) continued to receive immediately rewarded trials in one alley while receiving delayed reward in another, whereas in the successive design, experimental Ss were simply exposed to delayed reward. If NCEs are caused by inhibition generated by the receipt of a reward less valued than that expected, the importance of this difference makes very good sense, for continued exposure to immediate reward would have maintained a stronger expectation of such reward, and hence may have increased the inhibitory effectiveness of the delayed reward. There is evidence from studies of classical conditioning that the magnitude of inhibition conditioned to $\mathrm{CS}-$ is increased if nonreinforced trials to $\mathrm{CS}-$ are alternated with reinforced trials to CS+ (Reberg, 1970). It is tempting to suggest that there is an important connection between this finding and the greater ease of observing NCEs in simultaneous than in successive paradigms.

There is, of course, one obvious exception to the generalization that NCEs occur less readily in successive than in simultaneous designs. A reliable successive NCE is routinely observed when rats are shifted from a large to a small reward (e.g., Crespi, 1942). Why should a successive NCE occur more reliably for shifts in magnitude of reward than for shifts in concentration or delay of reward? And why should they occur more reliably in rats than in goldfish? One possible answer is that when a successive NCE does occur, it is not so much a consequence of the occurrence of inhibition or frustration, as of simple generalization decrement (Capaldi, 1967). If Ss are reinforced for responding in the presence of the remembered aftereffects of one condition of reinforcement, then responding will be distupted if a change in reinforcement significantly alters 
those aftereffects. Perhaps changes in magnitude of reward produce greater changes in aftereffects than do changes in concentration or delay of reward; and perhaps rats and fish differ in the extent to which their instrumental responses are controlled by the aftereffects of the outcomes of preceding trials.

The suggestion is less arbitrary than it may at first sight appear, for there is good independent evidence for the main underlying assumptions. That rats can discriminate between different aftereffects is shown by the fact that they can learn to respond on one trial in a way dependent on the outcome of the preceding trial. When exposed to regular alternations of reinforced and nonreinforced trials. they learn rapidly to respond on reinforced trials and to inhibit responding on nonreinforced trials (Capaldi, 1967). Similar patterning occurs when rats are exposed to alternating magnitudes of reward. thus showing that rats discriminate between the aftereffects of large and small rewards (Capaldi \& Cogan, 1963: Likely, 1970). But Cogan and Capaldi (1961) and Burt and Wike (1963) found no evidence of patterning when rats were trained on an alternating sequence of immediate reward and a 20 -sec delay of reward, and Likely (1970) found no patterning when rats were trained with different concentrations of sucrose as reward. Similarly, although goldfish may eventually (after nearly 1,000 trials) show some signs of patterning when trained with alternating reinforced and nonreinforced trials (Gonzalez, 1972), they are rather clearly less proficient than rats at such alternation learning (Mackintosh, 1971), and it may reasonably be doubted whether they would rapidly show significant patterning for alternating magnitudes of reward.

There is, therefore, a perfect correlation between those changes in reinforcement which support rapid alternation learning and those which produce a successive NCE. This suggests that successive NCEs are more a consequence of the generalization decrement produced by the change in reward than the inhibition or frustration produced by change in reward. If this is true, then it follows that the greater ease of observing simultaneous contrast effects may be attributed to the more favorable conditions for generating such inhibition or frustration.

\section{REFERENCES}

Amsel, A. Partial reinforcement effects on vigor and persistence. In K. W. Spence and J. T. Spence (Eds.), The psychology of learning and motivation. Vol. 1. New York: Academic Press, 1967. Pp. $1-65$.

Beery, R. G. A negative contrast effect of reward delay in differential conditioning. Journal of Experimental Psychology, 1968, 77, 429-434.
Black. R. W. Shifts in magnitude of reward and contrast effects in instrumental and selective learning. Psychological Review. $1968,75,114-126$

Burt. D. E.. \& Wike, E. L. Effects of alternating partial reinforcement and alternating delay of reinforcement on a runway response. Psychological Reports, 1963, 13, 439-442.

Capaldi. E. J. A sequential hypothesis of instrumental learning. In K. W. Spence and J. T. Spence (Eds.), The psy'chology of learning and motivation. Vol. 1. New York: Academic Press, 1967. Pp. 67-156.

Capaldi. E. J., \& Cogan. D. Magnitude of reward and differential stimulus consequences. Psychological Reports. 1963. 13. 85-86.

Chechile, R., \& Fowler. H. Primary and secondary negative incentive contrast in differential conditioning. Journal of Experimental Psychology, 1973, 97, 189-197.

Cogan. D.. \& Capaldi. E. J. Relative effects of delayed reinforcement and partial reinforcement on acquisition and extinction. Psychological Reports. 1961, 9. 7-13.

Crespi. L. P. Quantitative variation of incentive and performance in the white rat. American Journal of Psychology, 1942, 55. 467.517.

Flaherty, C. F.. Riley, E. P.. \& Spear, N. E. Effects of sucrose concentration and goal units on runway behavior in the rat. Learning \& Motivation, 1973, 4, 163-175.

Gonzalez, R. C. Patterning in goldfish as a function of magnitude of teinforcement. Psychonomic Science, 1972, 28, 53-55.

Gonzalez. R. C.. Potts, A., Pitcoff. K., \& Bitterman. il. E. Runway performance of goldfish as a function of complete and incomplete reduction in amount of reward. Psychonomic Science, 1972. 27. 305-307.

Gonzalez, R. C., \& Powers, A. S. Simultaneous contrast in goldfish. Animal Learning \& Behavior, 1973. 1. 96-98.

Harker, G. S. Delay of reward and performance of an instrumental response. Journal of Experimental Psychology. 1956, 51. 303-310.

Likely, D. Patterning of instrumental responding to sequences of varied food and sucrose rewards. Paper presented at meetings of the Eastern Psychological Association. A tlantic City. A pril 1970.

Lowes. G., \& Bitterman. M. E. Reward and learning in the goldfish. Science, 1967, 157, 455-457.

McHose, J. H., \& Tauber, L. Changes in delay of reinforcement in simple instrumental conditioning. Psychonomic Science. 1972. 27, 291-292.

Mackintosh, N. J. Reward and aftereffects of reward in the learning of goldfish. Journal of Comparative \& Physiological Psychology, 1971, 76, 225-232.

Raymond, B.. Aderman, M., \& Wolach. A. H. Incentive shifts in the goldfish. Journal of Comparative \& Physiological Psychology, 1972, 78, 10-13.

Reberg, D. Differential conditioning and extinction as inhibitory training procedures. Paper presented at meetings of the Eastern Psychological Association, Atlantic City, April 1972.

Shanab, M. E. Positive transfer between nonreward and delay. Journal of Experimental Psychology, 1971, 91, 98-102.

Shanab, M. E., \& McCuiston, S. Effects of shifts in magnitude and delay of reward upon runway performance in the rat. Psychonomic Science, 1970, 21, 264-266.

Spence, K. W. Behavior theory and conditioning. New Haven: Yale University Press, 1956.

(Received for publication July 13,1973; Accepted July $17,1973$. 